Hughes, B. P. (1962). Clinica Chimica Acta, 7, 597.

Laudahn, G., Hartmann, E., Rosenfeld, E. M., Weyer, H., and Muth, H. W. (1970). Klinische Wochenschrift, 48, 838 .

Lawrence, S. H., and Schulkins, T. (1956). Anesthesiology, 17, 531.

Mullan, D. P. (1969). Studies in Clinical Enzymology. London, Heinemann.

Person, D. A., and Judge, R. D. (1958). Archives of Surgery, 77, 892.

Rehn, J., Koehnlein, E., Graner, S., and Zeller, A. (1960). Medizinische Welt, 7,347 .
Rosalki, S. B, and Wilkinson, J. H (1960) Nature, 188, 1110

Schlief, H., and Kamm, P. (1957). Klinische Wochenschrift, 35, 1083.

Spector, A. A., and Pauli, W. A. (1963). Fournal of Applied Physiology, 18, 818.

Watanabe, R., Kaltus, A. A., and Semenson, C. (1957). fournal of Chronic Diseases, 6, 561 .

Wood, P. (1968). Diseases of the Heart and Circulation, 3rd edn. London, Eyre and Spottiswoode.

\title{
Diagnosis of Ruptured Aneurysm of Abdominal Aorta
}

\section{J. P. PRYOR}

\author{
British Medical fournal, 1972, 3, 735-736
}

\section{Summary}

A retrospective analysis of 44 cases of ruptured aneurysm of the abdominal aorta showed that only 14 were correctly diagnosed when admitted to hospital. The diagnosis was established in the ward after admission in 14 cases, in the operating theatre in one, and at necropsy in 15. The various clinical presentations are described, since early diagnosis and operation are essential to save life. Awareness of the condition and a careful examination of the abdomen are most important in making the diagnosis.

\section{Introduction}

Death is inevitable after rupture of an abdominal aortic aneurysm unless an operation is performed, and even then half of the patients die (Alpert et al., 1970). The correct diagnosis is often overlooked. Textbooks of medicine and surgery describe the common presentation with abdominal pain, shock, and a pulsatile abdominal mass but give few details of other presentations. Immediate diagnosis and early treatment are essential to save life, and in order to clarify the diagnostic problems we analysed the records of 44 patients with ruptured aneurysm of the abdominal aorta, 41 of whom had been admitted to King's College Hospital since 1958 and the other three were seen at the Brook Hospital in August 1970. Patients with ruptured dissecting or iliac aneurysms were excluded from the review. Seven of the patients were referred from another hospital and only one was moribund on arrival.

\section{Clinical Findings}

The 44 patients were aged 55 to 84 years (mean 70 ) and only five were women. The clinical findings at the time of admission are summarized in Table $I$. Seven of the patients were known to have an aneurysm.

Pain was the most constant feature and was absent in only three patients. In 14 patients the agonizing pain associated with rupture had been preceded by mild backache for up to three weeks. The pain was usually localized to the centre or lower abdomen, though on occasions it closely mimicked ureteric colic or radiated into the thighs. The pain was localized to the left and right sides equally often.

Thirteen patients presented with collapse ranging from a simple faint to a temporary cardiac arrest. These episodes were usually associated with severe pain and the patients often had few other symptoms. Vomiting was seldom severe, though three patients had a haematemesis and one was admitted on account of rectal bleeding. Half of the patients

King's College Hospital, Denmark Hill, London S.E.5 J. P. PRYOR, M.S., F.R.C.S., Senior Surgical Registrar were shocked. In five the tachycardia was masked by slow atrial fibrillation. The systolic blood pressure on admission varied. In 15 patients it was below $80 \mathrm{~mm} \mathrm{Hg}$ and in 10 above $150 \mathrm{~mm} \mathrm{Hg}$.

An abdominal aneurysm was felt in 20 patients but in six of them it was thought to be intact. An additional mass was felt in 16 patients and in nine it was observed to pulsate. In 12 cases the mass was distant from the aorta, and its significance was often overlooked. Some abdominal tenderness was invariable but pronounced muscle guarding occurred in nine patients. In no case were the bowel sounds noted as absent. Abnormalities of the femoral pulses were found in eight patients and absent lower limb reflexes were found in five. Only one patient had an ischaemic leg.

The correct diagnosis was made at the time of admission in only 14 patients, In another 14 it was made after their arrival in the ward, and in one it was made during laparotomy for suspected appendicitis. In the remaining 15 patients the diagnosis was made after death. The main cause for the diagnostic delay in $30(68 \%)$ of the patients was lack of awareness of the variable clinical picture of ruptured aortic aneurysms (see Table II).

Only four of the patients left hospital alive. Of the $\mathbf{4 0}$ who died 14 were operated on and 26 were not. In four of the 26 there was no time for operation, four were unfit for operation, four were "inoperable," and in 14 the diagnosis was not

TABLE I-Symptoms and Signs in 44 Patients with Ruptured Aneurysm of the Abdominal Aorta

\begin{tabular}{|c|c|c|c|c|c|c|}
\hline & & \multicolumn{2}{|r|}{$\begin{array}{l}\text { No. of } \\
\text { Patients }\end{array}$} & \multirow{3}{*}{\multicolumn{2}{|c|}{$\begin{array}{llll}\text { Sweating } & \ldots & \ldots & \ldots\end{array}$}} & $\begin{array}{c}\text { No. of } \\
\text { Patients }\end{array}$ \\
\hline & & & & & & \\
\hline $\begin{array}{l}\text { Abdominal } \\
\text { Back } \quad .\end{array}$ & - & . & * 24 & & .. & \\
\hline Lower limb & : & $\because$ & $\because \quad 10$ & $<80 \mathrm{~mm} \mathrm{Hg}$ & & \\
\hline Loin & . & .. & .. & $>150 \mathrm{~mm} \mathrm{Hg}$ & $\because$ & \\
\hline Ureteric colic & . & .. & .. & Palpable aneurysm & $\therefore$ & $\therefore$ \\
\hline Absent $\quad$. & . & .. & .. & Other mass & .. & .. 16 \\
\hline ollaps & & .. & .. 13 & Abdominal tenderness & .. & 40 \\
\hline 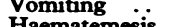 & - & .. & .. 13 & Abdominal guarding & . & .. \\
\hline $\begin{array}{l}\text { atemesis } \\
\text { n aneurysm }\end{array}$ & . & . & .. & Abnormal femoral pulses & 3.. & .. \\
\hline Pall & $\cdot$ & $\because$ & $\because 35$ & Abnormal leg reflexes & & $\cdots$ \\
\hline
\end{tabular}

TABLE II-Clinical Presentations of Ruptured Abdominal Aortic Aneurysm and Diagnostic Errors in 44 Cases

\begin{tabular}{|c|c|c|c|c|}
\hline \multicolumn{2}{|l|}{ Presentation } & \multirow{2}{*}{$\begin{array}{c}\text { No. } \\
18 \\
14\end{array}$} & \multirow{2}{*}{$\begin{array}{c}\begin{array}{c}\text { No. } \\
\text { Incorrectly } \\
\text { Diagnosed }\end{array} \\
4 \\
11\end{array}$} & \multirow[t]{2}{*}{ Diagnostic Errors } \\
\hline $\begin{array}{l}\text { Classical } \\
\text { Mass ... }\end{array}$ & $\begin{array}{l}\cdots \\
\cdots\end{array}$ & & & \\
\hline $\begin{array}{l}\text { "Acute } \\
\text { abdomen" }\end{array}$ & . & 26 & 11 & $\begin{array}{l}\text { Perforated duodenal ulcer, pancreatitis (2), } \\
\text { cholecvstitis (2), appendicitis (2), } \\
\text { diverticulitis (3), mesenteric thro }\end{array}$ \\
\hline Collapse & .. & 16 & 9 & $\begin{array}{l}\text { Coronary thrombosis (3), cerebral embolus } \\
\text { (2), bronchopneumonia (2), pulmonary } \\
\text { oedema, pulmonary embolus }\end{array}$ \\
\hline Urological & . & 15 & 10 & $\begin{array}{l}\text { Loin mass (3), ureteric colic (5), urinary } \\
\text { retention (2) }\end{array}$ \\
\hline $\begin{array}{l}\text { Gastrointestinal } \\
\text { bleeding } \\
\text { Vascular }\end{array}$ & & 4 & $\begin{array}{l}4 \\
5\end{array}$ & $\begin{array}{l}\text { Gastric erosions, duodenal ulcer (2), } \\
\text { mesenteric thrombosis } \\
\begin{array}{ll}\text { Dissecting aneurvsm } & \text { (2), mesenteric }\end{array}\end{array}$ \\
\hline Neurological & .. & 2 & 2 & $\begin{array}{l}\text { thrombosis (2), iliac artery thrombosi } \\
\text { Cerebral embolus (2) }\end{array}$ \\
\hline
\end{tabular}


made until after death. Of the 14 patients operated on 6 died before the graft was inserted, 4 died within 24 hours of the operation, and 4 died within two weeks.

\section{Discussion}

In the 18 patients who presented with the classical triad of shock, abdominal pain, and a pulsatile abdominal mass the correct diagnosis was readily made, though in four the aneurysm was thought to be intact. The surgical adage that "abdominal pain in any patient with an aneurysm is due to its rupture" is well worth remembering even if it is not always true. Unfortunately, in some patients pain may be absent on admission, the blood pressure normal, or no abdominal mass may be felt. A mass was not detected in almost two-thirds of the patients in the present series. This may have been owing to obesity, guarding of the abdominal musculature, or to the patient presenting before much blood had been extravasated. Leakage of blood into the retroperitoneum may be slow, and Razzuk et al. (1967) recorded a case in which it began three months before the diagnosis was established. With a slow leakage there may be bruising of the anterior abdominal wall (Eckbert and Kirklin, 1931), flanks (Loewenthal et al., 1939), scrotum (Bryant, 1903), or perineum.

Nine of the 12 cases in which a mass was felt at a site distant from the aorta were misdiagnosed. Loin masses often cause confusion, especially since not all of them are pulsatile. Occasionally the mass appears in the inguinal region, where it has been mistaken for an obstructed hernia (Betts and Rowlands, 1953) or a psoas abscess (Bryant, 1903). Two patients in the series were explored through a right iliac fossa incision for the removal of what was expected to be an acutely inflamed appendix. The similarity of a ruptured aneurysm to intra-abdominal sepsis has been well documented by Szilagyi et al. (1965).

Extravasation of blood into the retroperitoneal tissues may produce few abdominal signs. Backache and shock alert the clinician, though the resemblance to pancreatitis may be close, particularly when there is much vomiting. Death is imminent and often occurs rapidly when the aneurysm ruptures into the peritoneal cavity-a fact well known to coroners. In the past a ruptured aneurysm has been confused with ruptured ectopic gestation (Enselberg, 1956), but such errors are unlikely now that syphilitic aneurysms of the abdominal anrta are rare. When backache precedes abdominal pain a lumbar disc protrusion or back strain may be diagnosed.

Uhle (1941) and more recently Culp and Bernatz (1961) reviewed the urological aspects of aortic aneurysms. A problem often arises with loin pain. Six out of 17 of Enselberg's (1956) cases of ruptured aneurysm presented with colicky pain radiating to the testicle and five patients in our series had "ureteric" colic. Careful examination should prevent other urological errors of diagnosis such as urinary retention or oliguria, urinary tract infections, or prostatic cancer (Schammo et al., 1965). Haematuria due to the aneurysm rupturing into the renal vein occurs rarely (Graham and Downs, 1971).

Other vascular catastrophies may mimic a ruptured aneurysm, and differentiating a ruptured atheromatous aneurysm from a dissecting aneurysm may be difficult. In these cases radiography of the chest and abdomen is most helpful. In three of our cases the presentation was that of a thrombosed vessel (mesenteric or iliac) rather than a ruptured aneurysm, but the error is of less importance since opera ive treatment is required in all cases. Rarely an aortic aneurysm ruptures into the inferior vena cava. The characteristic features are abdominal pain and backache, rapidly increasing oedema of the legs and buttocks, and a pulsatile abdominal swelling associated with a harsh bruit. (Seal and Shepherd, 1970).
Cases of ruptured abdominal aneurysms simulating gastrointestinal disorders were reviewed by Sondheimer and Steinberg (1964). A ruptured aneurysm may resemble sigmoid volvulus or large-bowel obstruction. Reviewing the literature on rupture into the gastrointestinal tract, Kromach et al. (1957) found that most aneurysms ruptured into the third part of the duodenum. In only one of the four patients in our series with gastrointestinal bleeding had the aneurysm ruptured into the duodenum. In one of the others the bleeding was due to a gastric tear, in another to obstruction of the mesenteric vessels, and in the third no cause was found.

Occasionally a ruptured aneurysm of the abdominal aorta presents with a neurological disturbance, but such disturbances are more likely with a dissecting aneurysm (Moersch and Sayre, 1950). Beebe et al. (1958) drew attention to the loss of knee and ankle jerks in patients with a ruptured aortic aneurysm, but these signs are of little importance compared with a careful examination of the abdomen. Two elderly patients in our series were thought to have had a cerebral embolus. They were confused on admission, did not complain of pain, and had abnormalities of their reflexes. Pressure of the haematoma of the ruptured aneurysm on the lumbar plexus produced referred pain in the lower limbs in almost a quarter of our patients.

The diagnosis of ruptured aneurysm of the abdominal aorta depends on a careful examination and a high index of suspicion. The most useful investigation is a plain $x$-ray examination of the abdomen, and when the diagnosis is suspected a lateral view of the abdomen is valuable. Janover (1961) found that in 18 out of 20 patients with ruptured aortic aneurysm the radiographs were diagnostic, but unless the possibility of an aneurysm is in mind it may be easily missed. Calcification in its wall demonstrates the outline of an aneurysm and evidence of rupture is a loss of the psoas shadow (Held and Goldbloom, 1934). Extension of a soft-issue mass beyond the calcified rim of an aneurysm or displacement of the bowel gas anteriorly suggests a ruptured aneurysm (Janover, 1961).

Aortography rarely shows a leaking aneurysm and its only value is to show the relation of the aneurvsm to the renal vessels. In our series only one aneurysm extended above the origin of the renal vessels. Darling (1970) found that only three out of 83 aneurysms involved the renal vessels.

I am grateful to the physicians and surgeons at King's College Hospital and the Brook Hospital for allowing me to report on patients under their care, and to L. T. Cotton, Esq. for his advice.

\section{References}

Alpert, J., Brief, D. K., and Parsonnet, V. (1970). Fournal of the American Medical Association, 212, 1355.

Beebe, R. T., Powers, S. R., and Ginouves, E. (1958). Annals of Internal Medicine, 48, 834

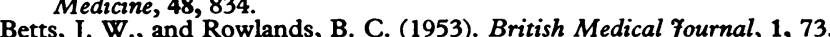

Bryant, D. (1903). Clinical fournal, 23, 71, 89

Culp, O. S., and Bernatz, P. E. (1961). Fournal of Urology, 86, 189.

Darling, R. C. (1970). American fournal of Surgery, 119, 397.

Eckbert, F. H., and Kirklin, J. W. (1931). United States Naval Medical Bulletin, 26, 667.

Enselberg, C. D. (1956). Annals of Internal Medicine, 44, 1, 163.

Grahame, J. W., and Downs, A. R. (1971). Fournal of Urology, 106, 628.

Held, I. W., and Goldbloom, A. H. (1934). Surgical Clinics of North America $14,389$.

anover, M. L. (1961). New England fournal of Medicine, 265, 12.

Kromach, J. J. S., O'Neil, J. F., Ciccone, E. F., and Snyder, R. J. (1957). Gastroenterology, 33, 574.

Loewenthal, J., Milton, G. W., and Shead, G. V. (1939). Medical fournal of Australia, 2, 137.

Australia, 2, 137 .
Moersch, F. P., and Sayre, G. P. (1950). Fournal of the American Medical Association, 144, 1141 .

Razzuk, M. A., Linton, R. C., and Darling, R. C. (1967). Fournal of the American Medical Association, 201, 817.

Schammo, J. F., Ferre, J., and Asif, S. (1965). Medical Annals, 34, 413.

Seal, P. V., and Shepherd, R. C. (1970). British fournal of Surgery, 57, 904 Sondheimer, F. K., and Steinberg, I. (1964). American fournal of Roentgenology, $92,1110$.

Szhilagyi, D. E., Elliott, J. P., and Smith, R. F. (1965). Archives of Surgery, 91, 263.

Uhle, C. A. W. (1941). fournal of Urology, 45, 13. 